\title{
The Uptake and Utilization of Histidine by Washed Amoebae in the Course of Development in Dictyostelium discoideum
}

\author{
By M. I. KRICHEVSKY AND L. L. LOVE \\ U.S. Department of Health, Education, and Welfare, Public Health Service, \\ National Institutes of Health, National Institute of Dental Research, \\ Laboratory of Microbiology, Bethesda, Maryland, U.S.A. 20014
}

(Received 23 September 1963)

\section{SUMMARY}

The characteristics of L-histidine uptake by Dictyostelium discoideum, after removal of the food supply, are described. There were only small differences in the rate of histidine uptake and incorporation into protein with changing $\mathrm{pH}$ value. It is concluded that the site of histidine stimulation of the rate of development must be at the cell surface or outside the cell. The production of urocanic acid from histidine is described. At the concentrations produced, urocanate had little or no effect on the rate of morphogenesis. However, at higher concentrations, urocanate and a variety of imidazole-containing compounds were stimulatory.

\section{INTRODUCTION}

In a previous communication (Krichevsky \& Wright, 1963), the ability of a variety of materials to stimulate the rate of development in Dictyostelium discoideum was described. The stimulant most studied was L-histidine. The action of this amino acid was shown to be not due to such phenomena as buffer capacity, tonicity, chelation, direct energy generation, or to stimulation of protein synthesis. The ability of histidine to inhibit the uptake of radioactive amino acids was shown; glucose did not possess this ability. In view of the foregoing, a study of the fate of exogenously supplied histidine was undertaken. Since the stimulatory effect of histidine was apparent within $4 \mathrm{hr}$ of the removal of residual bacteria from vegetative myxamoebae, it was decided to concentrate on this initial period.

\section{MATERIALS}

The procedures for growing and harvesting myxamoebae, determining the effect of materials on the rate of morphogenesis, isolating protein, and determining ${ }^{14} \mathrm{C}$ specific activity of protein were as described previously (Krichevsky \& Wright, 1963).

Imidazole-containing compounds were assayed in triplicate by the Pauly diazotization reaction as described by Macpherson (1942). It was found that urocanic acid has a molar extinction coefficient about two-thirds that of histidine.

Thin-layer chromatography was done as described in Operating Manual 103 of Brinkman Instruments, Inc., Westbury, New York. The layers were $250 \mu$ thick and composed of cellulose with $\mathrm{CaSO}_{4}$ (Type MN $300 \mathrm{G}$ ).

Uniformly ${ }^{14} \mathrm{C}$-labelled histidine (specific activity $=1.13$ microcuries $/ \mathrm{mg}$.) was 
obtained from Nuclear Research Corporation, Orlando, Florida. Urocanic acid was a gift from Dr Alan H. Mehler (NIDR, NIH, Bethesda, Md.). Filtration to remove cells was done with Millipore filters of pore size $0.45 \mu$ and a disc diameter $47 \mathrm{~mm}$. (Millipore Filter Corporation, Bedford, Mass.; catalogue number HAWPO 4700).

\section{RESULTS}

To determine the fate of exogenous histidine in Dictyostelium discoideum, initially three parameters were considered: the concentration of extracellular histidine; the uptake of histidine; the metabolism of histidine.

As shown in Fig. 1, the imidazole content of the Millipore filtrate of cell suspen-

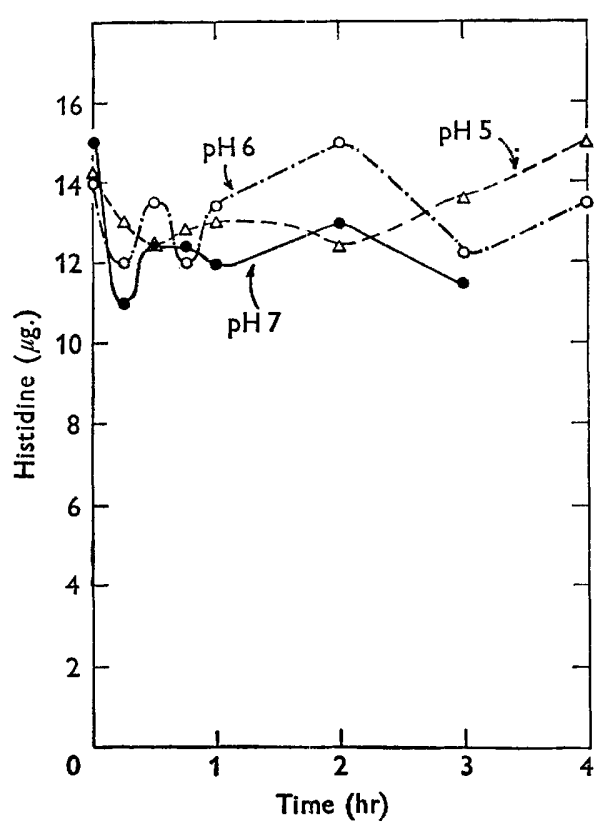

Fig. 1

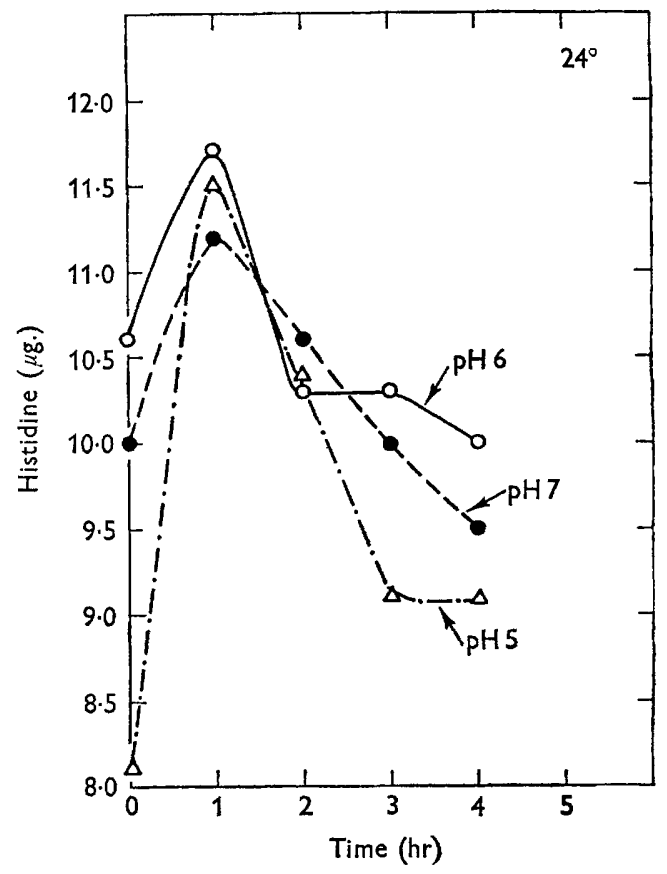

Fig. 2

Fig. 1. Extracellular histidine concentrations in cell suspensions. Amoebae were harvested from two cookie sheets, washed and finally suspended in Bonner's salt solution (Bonner, 1947); final volume $30 \mathrm{ml}$. A $4.0 \mathrm{ml}$. reaction mixture for each time and $\mathrm{pH}$ variable was prepared by adding, to a standard $9 \mathrm{~cm}$. Petri dish, $2 \mathrm{ml}$. of $0.08 \mathrm{M}-$ histidine of the appropriate $\mathrm{pH}$ value; $1 \mathrm{ml}$. Bonner's salts $(\times 4) ; 1 \mathrm{ml}$. cell suspension. At the times shown in the figure the incubation mixtures were filtered through Millipore filters. The filtrates were diluted $1 / 50$ and $0.1 \mathrm{ml}$. samples assayed in triplicate for imidazole-containing material.

Fig. 2. Histidine uptake into the soluble pool at 24. Amoebae were washed from two cookie sheets with cold distilled water, washed free from residual bacteria with cold distilled water and resuspended, final volume $9.0 \mathrm{ml}$. Samples of the cell suspension $(0.4 \mathrm{ml}$.) were placed on standard $9 \mathrm{~cm}$. diam. Petri dishes containing $0.4 \mathrm{M}$-histidine in $2.5 \%$ Noble agar at the $\mathrm{pH}$ value shown. The dishes were incubated at $24^{\circ}$ for the times shown. After incubation, the cells were washed from each Petri dish with $15 \mathrm{ml}$. cold distilled water, centrifuged, and washed once. Each cell sample was finally suspended in $5 \mathrm{ml}$. of distilled water and placed in a boiling water bath for $15 \mathrm{~min}$. After centrifugation, the supernatant fluids were assayed in triplicate for histidine. 
sions did not change appreciably with time. Possibly, the imidazole content of the filtrate at $\mathrm{pH} 5$ was slightly higher overall than at $\mathrm{pH} 6$ or 7 . However, the total range of variation was only about $20 \%$ of the total imidazole-reacting material initially present. Conversely, the imidazole content of the supernatant fluid of washed and boiled cells (representing the internal pool) incubated at initial pH 5 was lower than that at $\mathrm{pH} 6$ or 7 (Fig. 2). This was especially true at the earliest time shown, which was not a true zero but was in the range of 2-4 min. Krivanek \& Krivanek (1959) detected no histidine in the soluble pool of Dictyostelium discoideum at any stage of development. In addition, we found that there was little or no endogenous histidine under the conditions used here (Fig. 3). The foregoing experiment was performed at

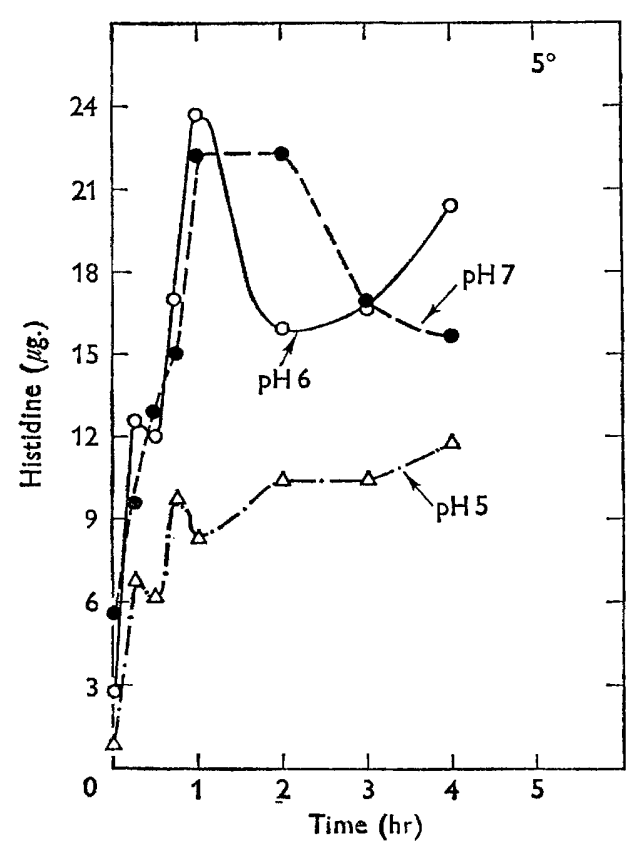

Fig. 3

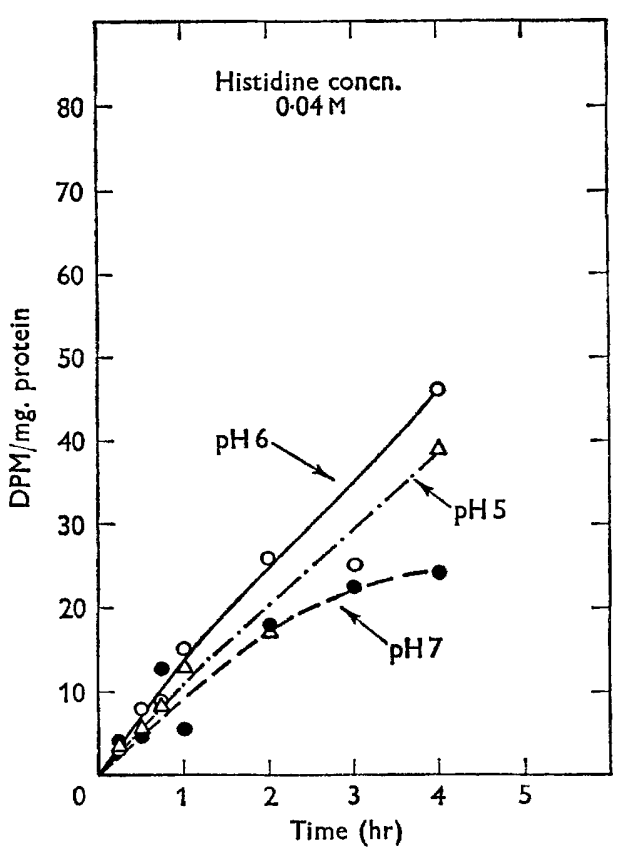

Fig. 4

Fig. 3. Histidine uptake into the soluble pool at $5^{\circ}$. The conditions of this experiment were like those of Fig. 2 with the exception that the incubation temperature was $\mathbf{5}^{\circ}$.

Fig. 4. Incorporation of exogenously supplied histidine- ${ }^{14} \mathrm{C}$ (uniformly labelled) in protein. Amoebae from two cookie sheets were harvested, washed, and finally suspended in cold distilled water to final volume $9.0 \mathrm{ml}$. To Petri dishes containing $3.6 \mathrm{ml}$. Bonner's salt solution with $0.04 \mathrm{M}$-histidine- ${ }^{14} \mathrm{C}$ (uniformly labelled; $0.05 \mu \mathrm{C} / \mathrm{ml}$.) at the $\mathrm{pH}$ value given, $0.4 \mathrm{ml}$. samples of the amoeba suspension were added. After incubation at $24^{\circ}$ for the times listed, $2 \mathrm{ml}$. of $12 \%(\mathrm{w} / \mathrm{v})$ trichloroacetic acid were added. The protein specific activities were determined. Protein concentration was determined by reading the purified materials at $220 \mathrm{~m} \mu$, with bovine serum albumin as standard, by the method of 'Tombs, Souter \& Maclagan (1959). DPM $={ }^{14} \mathrm{C}$ disintegrations per min.

$24^{\circ}$. When it was repeated at $5^{\circ}$ in order to slow any metabolism of histidine, the results shown in Fig. 3 were obtained. In this case, the maximal concentration of

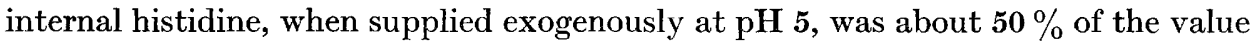
observed with external $\mathrm{pH} 6$ or 7 .

Since the amount of exogenous amino acids incorporated into protein is a reflexion 
of the internal pool concentrations (Krichevsky \& Wright, 1963), the kinetics of incorporation of exogenous ${ }^{14} \mathrm{C}$-labelled histidine into protein at $24^{\circ}$ was investigated (Fig. 4). There were only small differences in the rates of incorporation at the pHs studied.

During experiments on the leakage of ultraviolet-absorbing materials from amoeboid cell suspensions, it was noted that, whenever histidine was added, the Millipore filtrate of such suspensions contained material which absorbed maximally at about $300 \mathrm{~m} \mu$ in $0.5 \mathrm{M}-\mathrm{NaOH}$ and at about $267 \mathrm{~m} \mu$ in $3 \%$ trichloroacetic acid or $0 \cdot 1 \mathrm{~N}-\mathrm{HCl}$ (unpublished data). When the filtrate of an amoeboid cell suspension, incubated with $0.04 \mathrm{M}$-histidine at $\mathrm{pH} 5$, was chromatographed on a column of

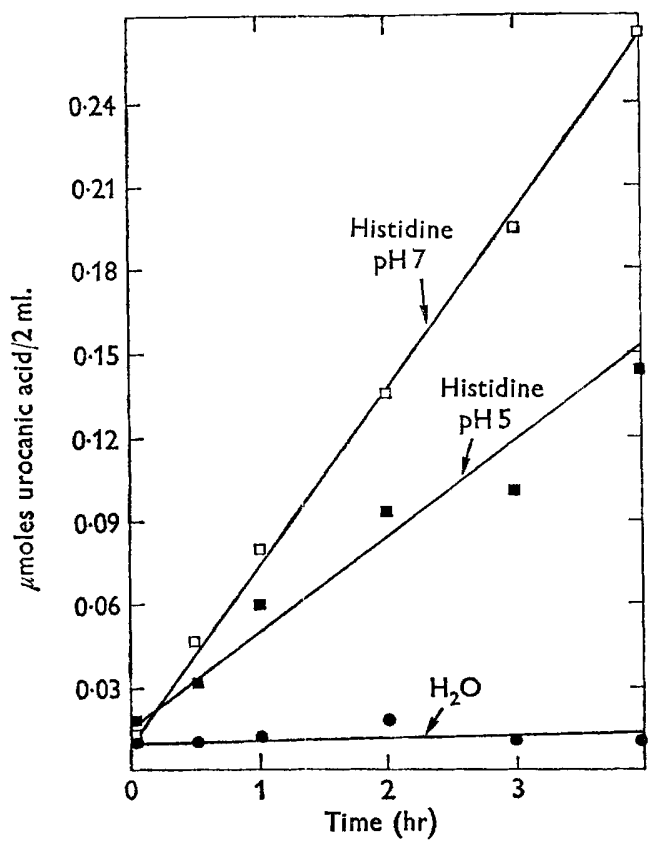

Fig. 5

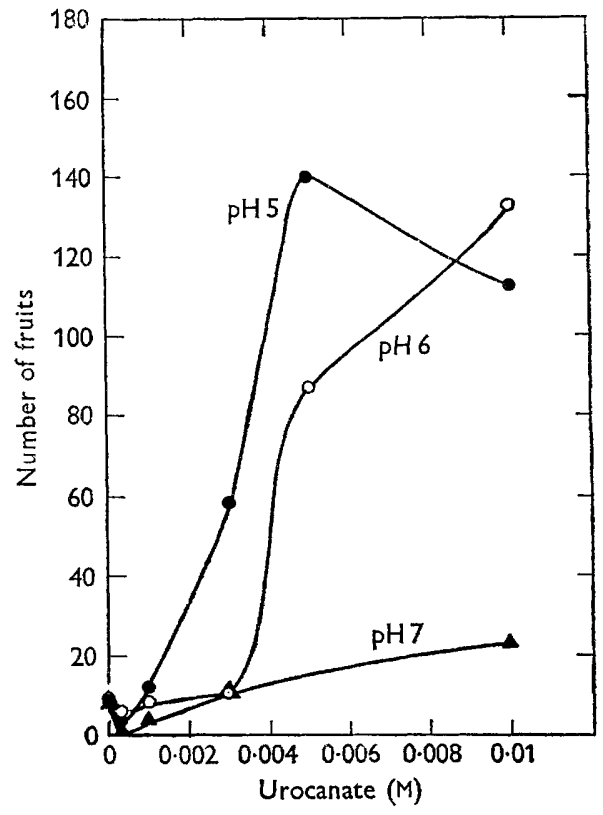

Fig. 6

Fig. 5. Urocanic acid production from histidine by washed myxamoebae. Amoebae were harvested from four cookie sheets, washed and resuspended in cold distilled water to final volume $20 \mathrm{ml}$. Beakers (1 1.), containing $42.3 \mathrm{ml}$. of either $0.04 \mathrm{M}$-histidine ( $\mathrm{pH} 7$ or $\mathrm{pH} 5$ ), or distilled water, were used as incubation vessels. To each beaker was added 4.7 $\mathrm{ml}$. of cell suspension to a final volume of $47 \mathrm{ml}$. The incubation was carried out at room temperature for the times shown. At the various time intervals, $1.0 \mathrm{ml}$. samples were withdrawn and pipetted into $1.0 \mathrm{ml}$. of cold $6 \%$ perchloric acid. The initial values were obtained by adding the perchloric acid to the incubation mixture before adding the cells. The samples obtained were centrifuged at $5^{\circ}$ and the supernatant solutions retained for analysis. Urocanic acid measurements were done on a 1/10 dilution, with $0.5 \mathrm{M}-\mathrm{KOH}$ as the diluent. The number of $\mu$ mole urocanate $/ 2.0 \mathrm{ml}$. original incubation mixture was determined by measuring the absorption at $290 \mathrm{~m} \mu$.

Fig. 6. Stimulation of morphogenesis by urocanate. Amoebae from one $9 \mathrm{~cm}$. diam. Petri dish were harvested, washed, and resuspended in $10 \mathrm{ml}$. cold distilled water. Six $0.01 \mathrm{ml}$. samples were placed on the surface of each $2.5 \%$ Noble agar plate containing the materials noted in the figure. The plates (unspread) were incubated for $26 \mathrm{hr}$ and the number of fruits on each plate determined. For a discussion of this assay see Krichevsky \& Wright, 1963. 


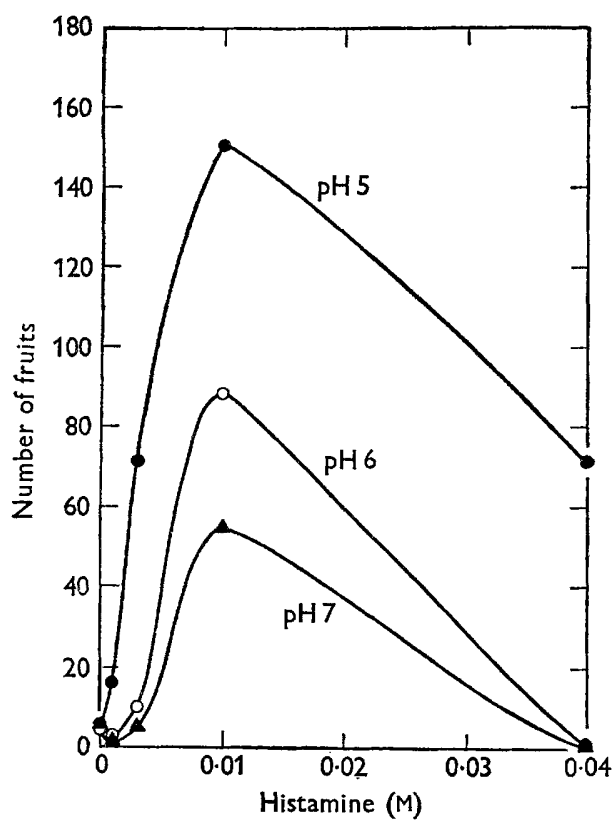

Fig. 7

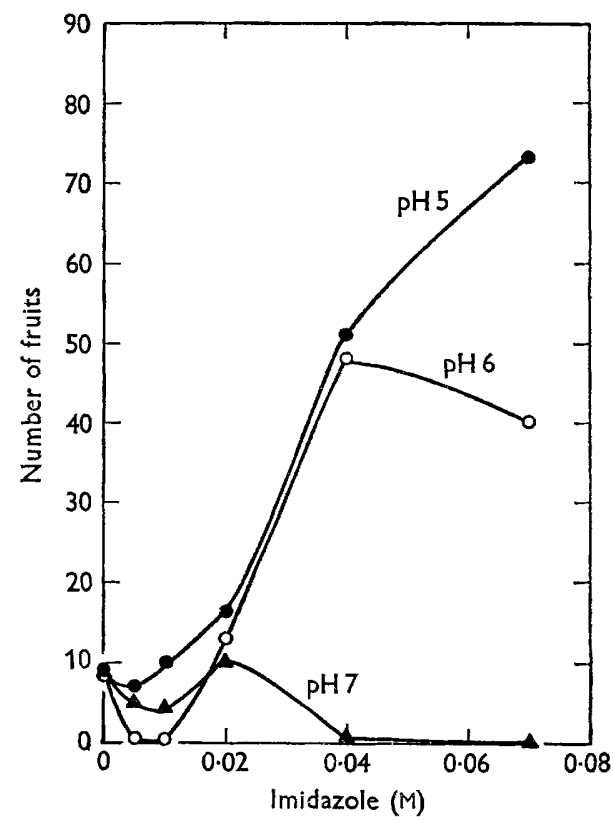

Fig. 8

Fig. 7. Stimulation of morphogenesis by histamine. All conditions were the same as those listed in Fig. 6 except that the materials incorporated in the test plates were as indicated.

Fig. 8. Stimulation of morphogenesis by imidazole. All conditions were the same as those listed in Fig. 6 except that the materials incorporated in the test plates were as indicated.

Table 1. Thin-layer chromatography of unknown material (isolated from Dowex-1-formate columns) on cellulose-CaSO

\begin{tabular}{|c|c|c|}
\hline & Unknown & Urocanic acid \\
\hline Solvent & \multicolumn{2}{|c|}{$\boldsymbol{R}_{f} *$ values } \\
\hline Distilled water $+\mathrm{NH}_{4} \mathrm{OH}$ to $\mathrm{pH} 10$ & $0 \cdot 76$ & 0.75 \\
\hline $\begin{array}{l}n \text {-Propanol }+0 \cdot 2 \mathrm{M}^{-\mathrm{NH}_{4} \mathrm{OH}} \\
\text { solution, } 3+1 \text {, by vol. }\end{array}$ & 0.52 & $0 \cdot 52$ \\
\hline $\begin{array}{l}\text { Phenol + water, } 75+25 \text {, wt. by } \\
\text { vol. }\end{array}$ & 0.78 & $0 \cdot 80$ \\
\hline $\begin{array}{l}n \text {-Butanol + acetic acid + water } \\
(60+20+20 \text {, by vol. })\end{array}$ & $0 \cdot 62$ & $0 \cdot 61$ \\
\hline
\end{tabular}

* Quenching of fluorescence under $253.7 \mathrm{~m} \mu$ used to visualize materials.

Dowex-1-formate, only one major peak of u.v.-absorbing (260 $\mathrm{m} \mu)$ material was eluted. The incubation mixture was identical with that described in Fig. 5. This peak was eluted almost immediately after beginning a gradient elution pattern of 0-1 N-formic acid, thus indicating a very weak acid. After lyophilizing the fractions containing the $260 \mathrm{~m} \mu$-absorbing material, the sample was taken up in a small volume of distilled water and spectra were determined under the seven conditions given by Mehler \& Tabor (1953). The shift in the absorption maximum with different 
pH values was identical with that of authentic urocanic acid (4-imidazole-acrylic acid). Furthermore, the unknown material and urocanic acid had the same mobilities in thin-layer chromatograms on cellulose-CaSO${ }_{4}$, developed in four different solvent systems (Table 1). Combinations of these solvent systems in two-dimensional chromatography also showed the identical mobility of the unknown with urocanic acid. As shown in Fig. 5, urocanic acid was produced linearly with time by myxamoebae incubated in the presence of $0.04 \mathrm{M}$-histidine, and almost twice as fast at $\mathrm{pH} 7$ as at $\mathrm{pH}$ 5. Even at $\mathrm{pH} 7$, however, the urocanic acid formed after $4 \mathrm{hr}$

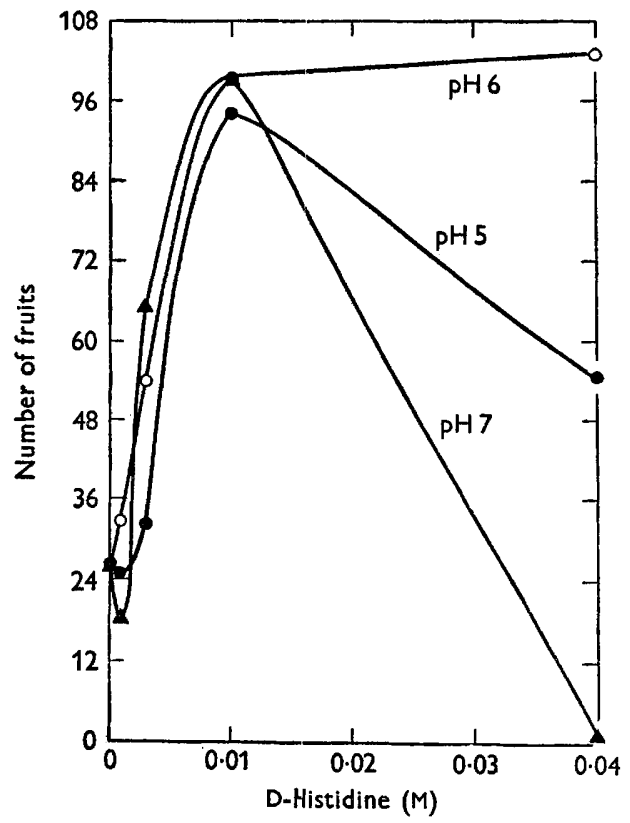

Fig. 9

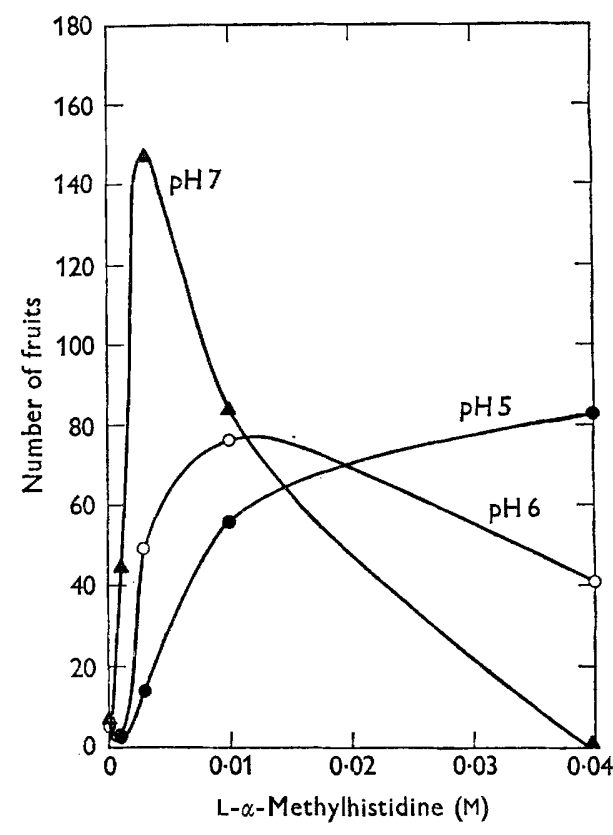

Fig. 10

Fig. 9. Stimulation of morphogenesis by D-histidine. All conditions were the same as those listed in Fig. 6 except that the materials incorporated in the test plates were as indicated.

Fig. 10. Stimulation of morphogenesis by $\alpha-\alpha$-methylhistidine. All conditions were the same as those listed in Fig. 6 except that the materials incorporated in the test plates were as indicated.

represented only approximately $0.3 \%$ of the histidine supplied. This amount of urocanic acid is equivalent to a concentration of $1.3 \times 10^{-4} \mathrm{M}$, if it be assumed that the urocanic acid is evenly distributed between the cells and their suspending medium.

Control incubations were performed with Escherichia coli grown under the same conditions as the amoebae, in a final concentration of 0.1 absorbancy at $660 \mathrm{~m} \mu$, which is more than 1000 times the concentration of $E$. coli organisms carried by the amoebal suspensions used. In no case was the production of any urocanic acid by E. coli detected.

To test the significance of urocanic acid for the morphogenetic process, the experiment illustrated in Fig. 6 was performed. It may be seen that urocanate was 
stimulatory in a manner analogous to L-histidine; i.e. the lower the $\mathrm{pH}$ value at which the stimulant was supplied, the greater was the degree of stimulation. Similarly, histamine (Fig. 7) and imidazole (Fig. 8) were more effective stimulants at lower $\mathrm{pH}$ values.

While 0.04 M-D-histidine and $0 \cdot 04 \mathrm{M}-\mathrm{L}-\alpha$-methylhistidine were not stimulatory of the rate of morphogenesis at $\mathrm{pH} 7$ (Figs. 9, 10) and were so at $\mathrm{pH} 5$ and 6 , the usual relationship of $\mathrm{pH}$ value to stimulation did not obtain for lower concentrations of these materials.

\section{DISCUSSION}

The production of urocanic acid (4-imidazole-acrylic acid) from histidine is a common catabolic reaction in mammalian liver (Mehler \& Tabor, 1953) and various bacteria (Barker, 1961). Dictyostelium discoideum also produces urocanic acid from histidine, as shown by the spectrum and chromatographic behaviour of isolated material. It appears that histidine does not stimulate the morphogenesis of $D$. discoideum by being converted in small amounts to urocanic acid, because equivalent amounts of urocanic acid alone do not stimulate morphogenesis as a whole. Bradley, Sussman \& Ennis (1956) stated that urocanate did not stimulate aggregation, but gave no details. The stimulation by L-histidine may simply be due to the imidazole portion of the molecule alone. The facts that all the imidazole compounds tested are stimulatory in the same general range of concentrations and that they all exhibit similar $\mathrm{pH}$ dependence (at least at the higher concentrations) would support this conclusion.

The effect of histidine on morphogenesis can be observed as soon as $4 \mathrm{hr}$ after separation of the amoebae from all sources of food. When $0.01 \mathrm{ml}$. samples of suspensions of amoebae are placed on $2.5 \%$ agar gel containing 0.04 M-histidine, a definite change in the nature of the spot may be seen which is not apparent in controls without added histidine. The periphery of the cell mass (large population densities are used) becomes irregular while the central area becomes 'lumpy'. These changes indicate the very early stages of aggregation. They are as readily apparent to inexperienced as to experienced observers. Thus, any action of histidine which results in stimulation of rate of morphogenesis must at least be initiated during the first $4 \mathrm{hr}$. Furthermore, a phenomenon which results from histidine addition which bears a casual relationship to the increased rate of development must be more efficient with greater hydrogen ion concentrations, since stimulation by histidine increases at lower $\mathrm{pH}$ values (Krichevsky \& Wright, 1963). That is, little or no stimulation is observed with histidine at $\mathrm{pH} 7$, but, as the $\mathrm{pH}$ value is lowered, the stimulation by histidine increases (at least to pH 5).

When the data here reported are considered in the light of the above considerations it seems that the stimulation of morphogenesis is due, at least in part, to the histidine outside the cell. If the internal histidine were important, the rate at which histidine entered the pool should be higher at $\mathrm{pH} 5$ than at $\mathrm{pH} 6$ or 7 ; this was clearly not the case; histidine disappeared from the external environment at very much the same rate regardless of the hydrogen ion concentration.

Though they did not test the effect of different hydrogen ion concentrations, Bradley et al. (1956) reported that histidine was taken into the internal pool from that supplied extracellularly in the form of $0 \cdot 01 \mathrm{~m}$-histidine agar at pH 6.2. Furthermore, these workers found that the pool concentrations decreased 
quite slowly from their initial values. We have observed essentially the same phenomenon (Fig. 2). In addition, histidine enters the free pool more slowly at $\mathrm{pH} 5$ than at $\mathrm{pH} 6$ or 7 . That the observed smaller pool concentrations at $\mathrm{pH} 5$ (as against $\mathrm{pH} 6$ or 7) are due primarily to decreased entry rather than increased metabolism is shown by the following observations. (a) At $5^{\circ}$ the differences in pool concentrations were greatly amplified while metabolism would be greatly slowed. The maximum histidine concentration, once achieved, was maintained (Fig. 3), in contrast to the shape of the curves obtained at $24^{\circ}$ (Fig. 2). (b) Histidine incorporation into protein was slower when the external $\mathrm{pH}$ value was $5 \cdot 0$ than at $\mathrm{pH} 7 \cdot 0$. Urocanate production was similarly affected by the $\mathrm{pH}$ difference. Therefore, both anabolic and catabolic utilization of histidine was slower under conditions where the amino acid was supplied at a $\mathrm{pH}$ value which greatly enhanced its ability to stimulate the rate of development.

The fact that histidine stimulates the rate of morphogenesis in a manner not correlated with its ability to penetrate the amoeboid cell leads to the conclusion that the rate of synthesis of even a single protein is not the rate-limiting step. If the synthesis of even one protein were rate limiting, its rate of synthesis would be correlated with internal histidine concentration. This would be true even if the histidine were acting not directly as a monomer of peptide chains; the same would apply if the histidine were acting to provide other intermediates required for the synthesis of a given protein (e.g. ammonia or carbon skeletons from urocanic acid). Any hypothesis which requires theinternal presence of histidine seems to be eliminated.

The simplest mechanism for histidine stimulation of the rate of morphogenesis appears to involve the ability of histidine to decrease the permeability of the amoeboid cells. If histidine is capable of inhibiting the exit of one or more essential metabolites, then it would control the rate of development by controlling the internal concentration of that metabolite. That histidine can affect permeability was shown previously (Krichevsky \& Wright, 1963), where the entry of ${ }^{14} \mathrm{C}$-labelled amino acids into cells was markedly decreased by the presence of histidine externally. It is reasonable to assume that histidine also can inhibit the exit of materials from the amoebae into the environment.

\section{REFERENCES}

Barker, H. A. (1961). In The Bacteria. Ed. by I. C. Gunsalus \& R. Y. Stanier. Vol. 2. New York: Academic Press.

BonNER, J. T. (1947). Evidence for the formation of cell aggregates by chemotaxis in the development of the slime mold Dictyostelium discoideum. J. exp. Zool. 106, 1.

Bradley, S. G., Sussman, M. \& EnNis, H. L. (1956). Environmental factors affecting the aggregation of the cellular slime mold, Dictyostelium discoideum. J. Protozool. 3, 33.

Krichevsky, M. I. \& Wright, B. E. (1963). Environmental control of the course of development in Dictyostelium discoideum. J. gen. Microbiol. 32, 195.

KrivaneK, J. O. \& Krivanek, R. C. (1959). Chromatographic analyses of amino acids in the developing slime mold, Dictyostelium discoideum Paper. Biol. Bull., Wood's Hole, 116, 265.

Macpherson, H. T. (1942). Modified procedure for the colorimetric estimation of arginine and histidine. Biochem. J. 36, 59.

Mehler, A. H. \& TABor, H. (1953). Deamination of histidine to form urocanic acid in liver. J. biol. Chem. 201, 775.

Tombs, M. P., Souten, F. \& Maclagan, N. F. (1959). The spectrometric determination of protein at $210 \mathrm{~m} \mu$. Biochem. $J .73,167$. 